\begin{tabular}{ccr} 
FOLIA & ENTOMOLOGICA & HUNGARICA \\
& ROVARTANI KÖZLEMÉNYEK & \\
Volume 81 & 2020 & pp. $119-122$ \\
\hline
\end{tabular}

\title{
First record of Spodoptera littoralis in Hungary (Lepidoptera: Noctuidae)
}

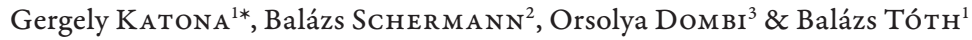 \\ ${ }^{1}$ Hungarian Natural History Museum, Department of Zoology, H-1088 Budapest, Baross utca 13, \\ Hungary.E-mails: katona.gergely@nhmus.hu,toth.balazs@nhmus.hu \\ ${ }^{2}$ Szent István University, Environmental Sciences PhD School, H-2100 Gödöllo", \\ Páter Károly utca 1, Hungary.E-mail: schermann.balazs@gmail.com \\ ${ }^{3}$ József Szalkay Lepidopterological Society of Hungary, H-2030 Érd, Avar utca 2, Hungary. \\ E-mail:orsolya.dombi@gmail.com
}

\begin{abstract}
Three larvae of the noctuid moth Spodoptera littoralis (Boisduval, 1833) have been found in Kistarcsa, Central Hungary in August, 2020. One caterpillar developed to adult stage, it is deposited in the Hungarian Natural History Museum, Budapest. This is the first record of this Afrotropical and subtropical species in Hungary. With 4 figures.
\end{abstract}

Key words - migrant, moth, new country record, pest

\section{INTRODUCTION}

The African cotton leafworm (also known as Egyptian cotton leafworm or Mediterranean brocade moth) Spodoptera littoralis (Boisduval, 1833) was described as Hadena littoralis from Maurica, Bourbon, western coast of Madagascar (BoIsDUval 1833). It is known to occur in Africa, the Middle East and the Mediterranean Region. It is a rare migrant, but occasionally found in central and northern Europe due to import or escape from garden nurseries (FIBIGER \& HACKER 2007). It is a dangerous pest of several plants (EPPO 2020).

\section{MATERIAL AND METHODS}

The second author (BS) found three unidentified but uniform moth larvae feeding on Rhipsalis sp. (Cactaceae) plants on 11 August 2020, at Kistarcsa, Central Hungary. Previously he discovered some unidentified leaf mining larvae

* Corresponding author. 
in his lemon tree (they provided the first Hungarian record for the micromoth citrus leafminers, KATONA et al.2020) and, together with these miners he wanted to get identified also these three large caterpillars. The larvae were photographed and the images were sent to the first author (GK). Subsequently the third author (OD) identified the caterpillars documented as one of the Spodoptera species, $S$. littoralis or S. litura (Fabricius, 1775), both could be new to the Hungarian fauna.

Two caterpillars died during the rearing, but the third one was transported to the Hungarian Natural History Museum (HNHM, Budapest) on 17 August 2020 where it was fed with Rhipsalis sp. and English cucumber (Cucumis sativus L.). Next morning the larva turned into pupa, and the moth emerged in the night before 28 August 2020. The moth was identified as the macromoth species Spodoptera littoralis (Boisduval, 1833). The specimen was dissected for the confirmation of its identity (by BT). The specimen is deposited in the Lepidoptera Collection of HNHM.

The larvae (Fig. 1) were photographed by a Samsung Galaxy J4+ telephone. The pupa (Fig. 2) and adult (Fig. 3) were documented with an Olympus Camedia C 7070 camera, Fig. 4 was composed using Olympus DP70 photographic microscope with DPController and DPManager programs.
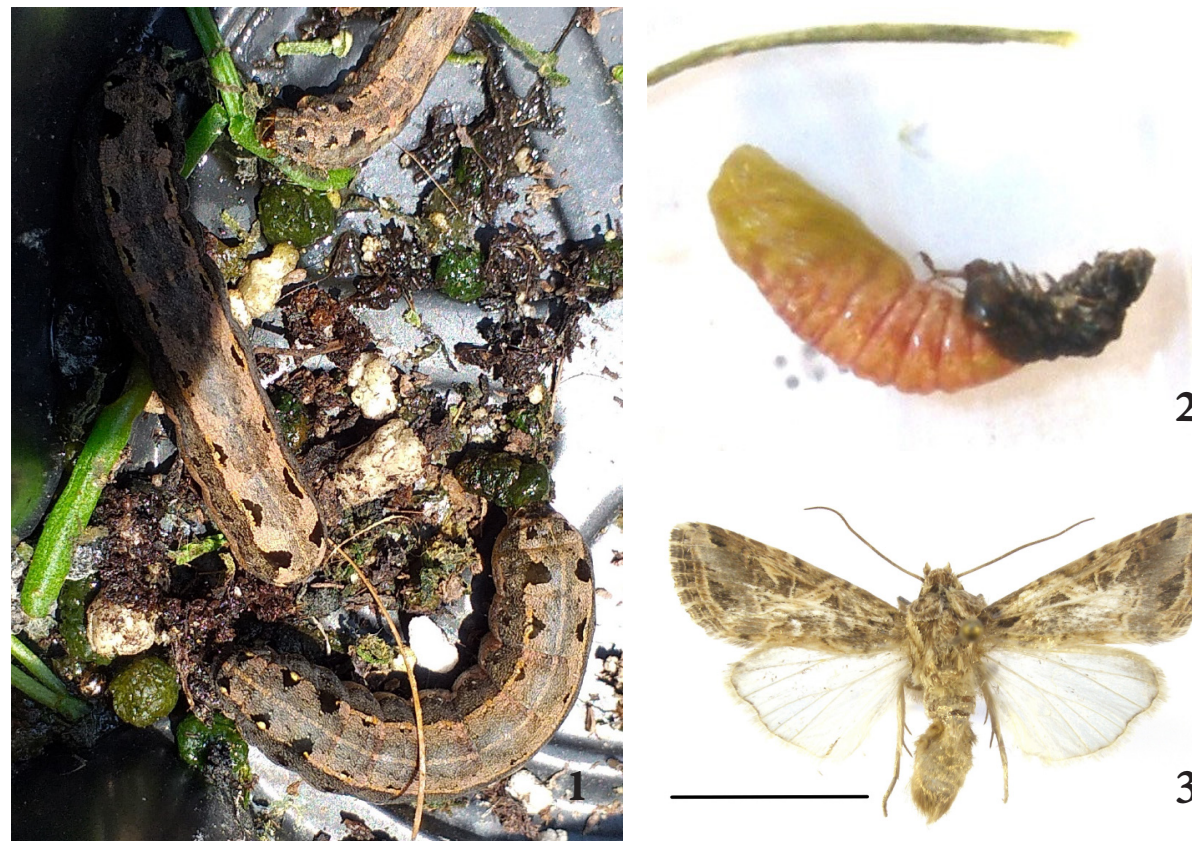

2

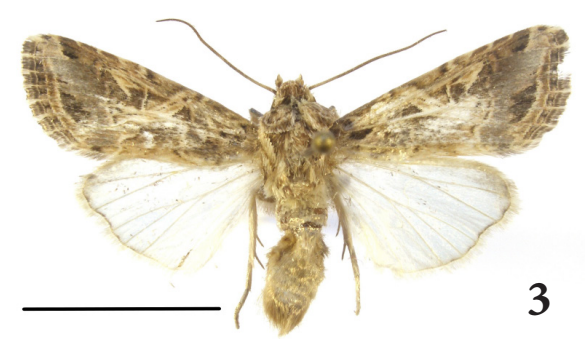

Figs 1-3: Spodoptera littoralis in Hungary: 1 = three caterpillars in Kistarcsa (photo by Balázs Schermann), 2 = the fresh pupa from the sole survived specimen, 3 = adult before dissection, scale bar $=10 \mathrm{~mm}$ (photos by Gergely Katona) 


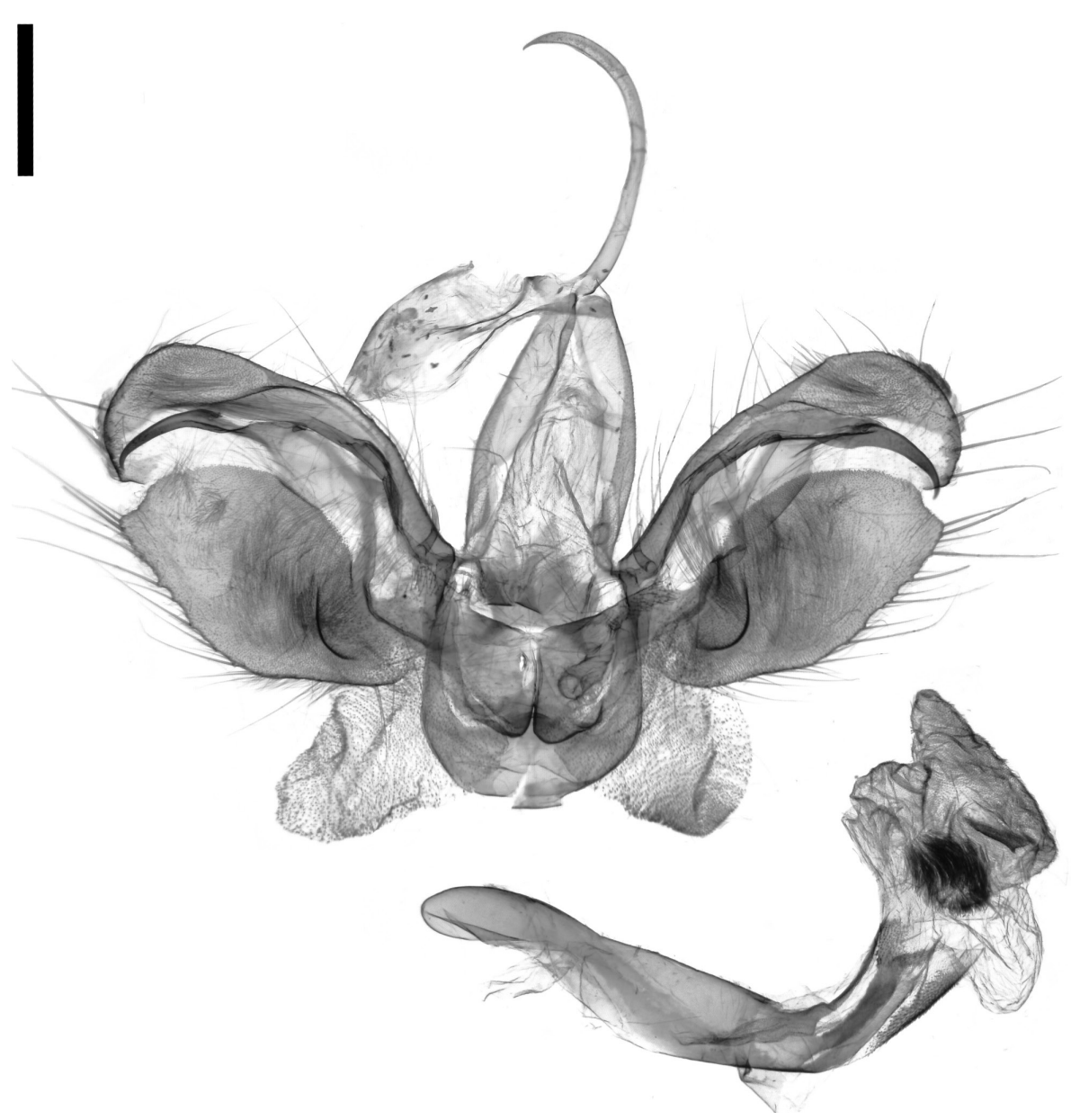

Fig. 4. Spodoptera littoralis: male genitalia of the specimen shown in Fig. 3. (slide No. TB2017m), aedeagus below, scale bar $=1 \mathrm{~mm}$ (photo by Balázs Tóth)

\section{RESULTS AND DISCUSSION}

Dissection of the moth specimen (slide No. TB2017m; Fig. 4) confirmed the preliminary identification as $S$. littoralis. The diagnostic characters of the male genitalia are the quadrangular juxta with two short ventro-lateral processes and the slightly curved shape of the costal process in the valva (in contrast with the sub-triangular, narrow juxta and strongly curved costal process of $S$. litura) (ANONYMUS 2015). 
In the collection of HNHM we found 178 Spodoptera littoralis specimens from the following countries: Egypt 56, France (mainland) 3, Greece (Crete) 8, Greece (Rhodes) 3, Iran 2, Iraq 4, Israel/Palestine 8, Italy (mainland) 1, Italy (Sardinia) 1, Italy (Sicily) 11, Morocco 8, Spain (mainland) 5, Spain (Mallorca) 4, Spain (Tenerife) 16, Syria 2, Tunisia (Djerba) 1, Tunisia (mainland) 3, Turkey 34, only with label "Mediterran" 3, and without label 5 specimens. In the Hreblay Collection (deposited in the HNHM) there are three specimens of Spodoptera littoralis, one each from Italy (Sicily), Morocco, and Tunisia (BÁLIn t et al.2014). In the Carpathian Basin material there was no specimen. Hence this individual serves as a voucher of the species' occurrence in Hungary.

The host plant was imported to Hungary from the Netherlands in 2020. The species is likely to appear elsewhere in the near future not only in Hungary, but also in the neighbouring central European countries.

Spodoptera littoralis is a pest of alfalfa, apples, avocados, beets, bell peppers, cabbage, carrots, cauliflower, cereal, clover, corn, cotton, cucurbits, eggplants, figs, geraniums, grapes, lettuce, oaks, okra, onions, peas, peanuts, pears, pines, poplars, potatoes, radish, roses, soybeans, spinach, sunflowers, taro, tea, tobacco, tomatoes and watermelons (Nom A et al. 2010).

Acknowledgements - We thank Zsolt Bálint (HNHM) for checking the manuscript.

\section{REFERENCES}

ANONYMUS 2015: PM 7/124 (1) Spodoptera littoralis, Spodoptera litura, Spodoptera frugiperda, Spodoptera eridania. - Bulletin OEPP/EPPO Bulletin 45(3): 410-444.

https://doi.org/10.1111/epp.12258

Bálint Zs., Katona G. \& Gubányi A. 2014: A life for Noctuidae. The Owlet moths of Márton

Hreblay (1963-2000). Names, specimens and types. - Hungarian Natural History Museum, Budapest, $270 \mathrm{pp}$.

Boisduval J. B. 1833: Faune entomologique de Madagascar, Bourbon et Maurice. Lépidoptères. Roret, Paris, 122 pp.

EPPO 2020: EPPO Global Database (available online). - Online: https://gd.eppo.int [Accessed 1 November 2020].

Fibiger M. \& Hacker H. 2007: Noctuidae Europae volume 9 Amphipyrinae, Condicinae, Eriopinae, Xyleninae (part). - Entomological Press, Sorø, 410 pp.

Katona G. Schermann B. \& Tóth B. 2020: First record of Phyllocnistis citrella in Hungary, a micromoth species pest on Citrus (Lepidoptera: Gracillariidae). - Folia entomologica bungarica 81: 115-118.

Noma T., Colunga-Garcia M., Brewer M., Landis J. \& Gooch A. 2010: Egyptian cottonworm: Spodoptera littoralis. - Michigan State University, East Lansing, 2 pp. 